\title{
A VIAGEM SENTIMENTAL, 0 FOLHETIM E A POLIIIICA DOS JORNAIS: NERVAL LEITOR DE STERNE
}

http://dx.doi.org/10.11606/issn.2237-1184.v0i25p197-213

Marta Kawano

Universidade de São Paulo (USP)

\section{RESUMO}

$\mathrm{O}$ artigo propõe-se a realizar uma aproximação entre a narrativa Les nuits d'octobre, de Gérard de Nerval, e Uma Viagem Sentimental, de Laurence Sterne. Alguns temas comuns às duas narrativas estarão no centro desta análise comparada: a oposição entre liberdade de movimento (errância e fantasia) e ameaça de prisão; as relações com figuras de autoridade; interrogação sobre a identidade do eu que realiza cada uma das viagens.

ABSTRACT

This paper is invested in approximating Gérard de Nerval's narrative Les nuits d'octobre and Lawrence Sterne's A Sentimental Journey. Some common themes are at the centre of this comparative analysis: opposition between freedom of movement (aimlessness and fantasy) and threat of arrest; responses to authority figures; and inquiry into the identity of the self who undertakes each one of the journeys.

\section{PALAVRAS-CHAVE}

Narrativa de viagem.

Folhetim.

Romantismo.

Gérard de Nerval.

Laurence Sterne.

Les nuits d'octobre.

A Sentimental Journey.

\section{KEYWORDS}

Travel narratives.

Feuilleton; Romanticism.

Gérard de Nerval.

Lawrence Sterne.

Les nuits d'octubre.

A Sentimental Journey. 
(...) les poètes sont comme des fous à la cour des rois: c'est du mépris qu'on fait d'eux, qu'ils tiennent leur franc-parler. ${ }^{1}$

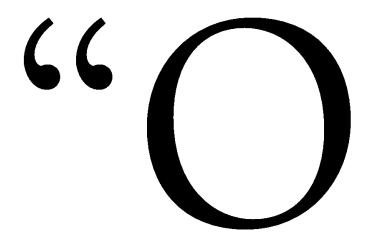

h! La passion!". Foi assim que, em 1841, Jules Janin escolheu traduzir uma conhecida exclamação - "Dear Sensibility!" - de A Sentimental Journey de Sterne, publicada muitas décadas antes do outro lado do Canal da Mancha. Tem-se aqui um exemplo bastante eloquente de como uma tradução discutível pode revelar - ou, por outras vias, traduzir - bem mais do que os próprios termos em questão... Quando há deslocamento espacial e temporal, parece ser inevitável que as releituras de qualquer autor realizem também deslocamentos significativos em relação ao contexto original de publicação, especialmente quando essas releituras são realizadas pelas mãos de outros escritores. O que se pretende aqui é acompanhar um momento em particular da viagem que o texto de Sterne realizou no século XIX francês, na figura de um de seus leitores mais dedicados: Gérard de Nerval. Nesta leitura da Viagem Sentimental, trata-se então menos de uma hermenêutica voltada para a interpretação do próprio texto e de seu contexto original de publicação e mais da tentativa de compreensão de um momento da recepção dessa obra.

Portanto, há aqui um viés interpretativo que é preciso explicitar logo de saída. Mas a aposta que se faz aqui é a de que o risco de uma leitura enviesada seja em alguma medida compensado por frutos improváveis que se poderão colher pelo caminho, e que dariam prova da vida própria dos textos, em particular quando estes encontram raízes em novos contextos, neles podendo ressoar de forma inaudita. Neste caso, importa compreender como um feuilleton ${ }^{2}$ nervaliano intitulado Les Nuits d'octobre traça um percurso de escrita que retoma diversos aspectos da viagem de

\footnotetext{
${ }^{1}$ Denis Diderot. Discours sur la poésie dramatique. Euvres Esthétiques, Paris: Vernière, 1959. p. 260.

2 "Nerval é um mestre do folhetim que floresceu na França durante a Monarquia de Julho (...) o folhetim exige precisão de objetivo, pureza na captação do instante fugidio, rapidez de espírito na invenção de correspondências metafóricas ousadas, e um registro que oscila constantemente entre o tom urbano e espirituoso e a sensibilidade subjetiva. Seu modelo é o discurso complexo e descontínuo de Sterne, tal como ele o desenvolveu sobretudo em A Sentimental Journey, tão lida e imitada na França. Nerval foi o primeiro, na França, a promover o folhetim ao nível de uma forma de arte". Karlheinz Stierle. La Capitale des signes. Paris et son discours. Paris: Maison des Sciences de l'homme, 2001. (Trad. M. RocherJacquin e prefácio de J. Starobinski), p. 387. Registre-se ainda, em outra direção, que o folhetim parisiense Les Nuits d'octobre foi lido e admirado por André Breton e Aragon, e deixou marcas em obras como Nadja e Le Paysan de Paris.
} 
Sterne e, ao mesmo tempo, traz muito profundamente as marcas (com consequências para o próprio estilo, como veremos) de um momento bem determinado da sociedade francesa: o estabelecimento do Segundo Império de Napoleão III.

Em 1852, ano em que foi publicado Les Nuits d'octobre [As noites de outubro], a história da recepção da Viagem Sentimental de Sterne na França já era longa e profícua. Dela gostaria de retomar alguns aspectos que serão relevantes para esta aproximação entre Sterne e Nerval. O primeiro diz respeito à existência de um conjunto de narrativas da virada do século XVIII para o XIX nas quais a viagem sterniana se presta a leituras políticas das mais variadas orientações, como mostrou um estudo sobre a recepção de Sterne na França: "Sterne foi adotado igualmente por monarquistas esclarecidos, monarquistas, liberais e revolucionários". Em todos os casos, a matriz sterniana funcionaria ideologicamente. Algumas dessas narrativas, por exemplo, "focalizam categorias sociais que eram tradicionalmente sub-representadas na literatura (...) : o pobre, o louco, o velho, o doente." 3 . A menção à existência dessas obras nos adverte inicialmente para o fato de que, se há, em Nerval, uma releitura politica de Sterne, nosso autor não seria o primeiro a explorar essa via.

Em segundo lugar, gostaria de atentar, na recepção do autor irlandês na França do XIX, para um conjunto de questões que dizem respeito ao eu posto em cena e à afirmação de sua originalidade, frequentemente espelhada na originalidade da escrita. Quanto ao sujeito, pode-se partir de uma passagem da "Introdução" de Jules Janin à sua tradução de Viagem Sentimental, publicada em 1841: "Sterne deixou um retrato traçado por ele mesmo, e com mão de mestre. Eis esse retrato, tal como ele o fez: é ao mesmo tempo o retrato de Yorick (eu-narrador de Viagem sentimental), de Tristram e de Sterne, três heróis que compõem um só". "Aponta-se aqui uma ambiguidade pela qual se confundem autor, personagem e narrador. Por essa via, a afirmação da originalidade da obra e do estilo estará estreitamente vinculada à peculiaridade do indivíduo que a produz. Tal ambiguidade será uma constante nas menções a Sterne na França do período.

De maneira geral, uma das marcas mais características de sua recepção no Romantismo francês é a originalité, noção que se fará presente na definição de Nodier de livre excentrique como um livro que "que se faz fora de todas as regras comuns da composição e do estilo" 5 . Três anos antes, Théophile Gautier abrira o seu artigo intitulado "De l'originalité en

\footnotetext{
${ }^{3}$ Como mostrou Lana Asfour em Laurence Sterne in France. Londres et New York: Continuum, 2008, p. 107 e p. 189.

${ }^{4}$ Laurence Sterne. Voyage Sentimental. Paris: Bourdin, 1841, p. XL. Tradução e prefácio de Jules Janin.

${ }^{5}$ Charles Nodier. "La bibliographie des fous". Bulletin du bibliophile, 1835.
} 
France" [Da originalidade na França] com as seguintes palavras: "Mestre Yorick [Gautier se refere ao narrador de Viagem Sentimental], o descendente do bufão de Hamlet, disse (já há alguns anos) que os franceses eram como moedas que, de tanto passar de mão em mão, perderam a sua marca"... ${ }^{6}$

A figura de Sterne - tanto pela originalidade de sua escrita quanto pelas considerações a respeito do espírito francês contidas em Viagem sentimental - forneceu subsídios para a afirmação da originalidade como valor que se contrapõe, do lado dos artistes, à honradez burguesa predominante ao longo da Monarquia de Julho (1830-1848) e do Segundo Império (1852-1870). E a categoria da originalidade, assim trazida para o primeiro plano, instaura uma dinâmica peculiar nas narrativas que partem do modelo sterniano: qualquer narrativa que imite Sterne irá imitá-lo de forma original.

É a retomada da viagem sterniana por Nerval que procurarei acompanhar nesta leitura de Les Nuits d'octobre, acreditando que os modos novos pelos quais Nerval relê e reinventa a obra sterniana podem ser lidos sobre o fundo do momento histórico em que o seu texto é produzido.

A aproximação entre os dois textos estará centrada na interrogação sobre a identidade do sujeito que neles se põe em cena e na escrita humorística, entendida como uma aquela pela qual se captam as oscilações de humor do eu-narrador. Ao tomar como eixo a questão da subjetividade e da escrita do eu, procuro ser fiel à maior parte das menções de Nerval a Sterne, como aquela segundo a qual Sterne "era um dos raros escritores que, a partir da Inglaterra, chamamos humoristiques". ${ }^{7}$ A respeito da narrativa de viagem sterniana, Nerval afirma que ela pertence a uma maneira particular e fantasque de ver e sentir ${ }^{8}$. Sterne serve ainda de guia a Nerval, em Voyage en Orient, para que ele registre as impressions sentimentales de sua viagem ${ }^{9}$. Atentemos ainda para os epítetos empregados por Nerval para caracterizar Sterne: "o bom Sterne", "o bom Yorick, desconhecido, inquieto, perdido no tumulto da vida parisiense"10. Ora, esse modo de caracterização se assemelha curiosamente à figura de Nerval como "bon et doux Gérard" (bom e doce Gérard) e também à do "pauvre Gérard" (pobre Gérard), desenhada por alguns de seus contemporâneos... A semelhança entre as imagens dos dois escritores (e a ambiguidade, em ambos os casos, entre autor, narrador e personagem) se faz presente em uma das referências mais significativas de Nerval a Sterne,

\footnotetext{
${ }^{6}$ Cabinet de Lecture, julho de 1832. Note-se aqui a curiosa explicação para o caráter polido (para a politesse) dos franceses. Curioso também o fato de um escritor francês do período retomar e sublinhar, como uma crítica aos seus conterrâneos, a observação de Sterne.

7 "Jacques Cazotte". Les Illuminés, NPl II, p. 1075 (var. a, p. 1743). A abreviação NPl remete à nova edição das Euvres complètes de Gérard de Nerval, organização de Jean Guillaume e Claude Pichois. Paris, Gallimard, 1989-1993 (NPl I,II,III).

8 "À M. B*******". Le Messager, 18 septembre 1838. NPl I, p. 455.

${ }^{9}$ Voyage en Orient. NPl II, p. 201.

10 "Les Confidences de Nicolas". Les Illuminés. NPl II, p. 1038 et Voyage en Orient, NPl II, p. 356.
} 
aquela contida em Lorely, na resposta a um artigo de 1842 de Jules Janin (que alardeou uma das crises de loucura de Nerval, com consequências dramáticas para o escritor): Alas! poor Yorick!... ${ }^{11}$

A breve citação em inglês condensa toda uma cadeia de textos que se inicia no solilóquio de Hamlet, passa por um episódio de Tristram Shandy e pela Viagem Sentimental. Mais imediatamente, ela ecoa as palavras iniciais - Pauvre Yorick! - da introdução do mesmo Janin à sua tradução da Viagem Sentimental de Sterne, publicada no mesmo ano em que este escrevera o fatídico artigo sobre Nerval. Com todas essas ressonâncias, a exclamação "Pobre Yorick!" é aqui tomada como mote nesta leitura conjunta de Les Nuits d'octobre e da Viagem Sentimental, que terá como eixo o questionamento sobre a situação do escritor na França de 1852 mediante a interrogação sobre o estatuto do sujeito na narrativa.

A crítica aponta com frequência o caráter ambíguo e enigmático de Les Nuits d'octobre. Diante de sua complexidade e opacidade, qual chave de interpretação escolher? Optamos aqui por uma dupla entrada, que consiste em realizar uma leitura política do texto pela tentativa de compreensão do modo como Nerval lê e inflexiona a Viagem de Sterne. O esquema geral é fornecido por Angélique, texto em que Nerval se vale do relato de viagem e do modo digressivo como arma certeira para uma crítica política e social da França pós-1848. Em uma palavra, a digressão sterniana permite a esquiva da interdição (imposta pelo emenda Riancey ${ }^{12}$ ) e a crítica da mesma interdição (e da forma de poder que a fundamenta). A estratégia é fundamentalmente irônica.

Mas Les Nuits d'octobre é um texto mais ambíguo do que Angélique. A narrativa oscila muitas vezes entre o cômico e o grave. Na leitura do texto, o leitor acompanha um duplo movimento: o movimento caprichoso da própria escrita (a digressão) e a deambulação do eu-narrador. Tal espelhamento entre os percursos do texto e os do eu-narrador se desdobra no duplo sentido das ameaças, que são tanto à liberdade de movimentos (prisão) quanto à liberdade da escrita, pela acusação de fantaisisme et essayisme. A todas essas oscilações e duplicidades se soma o efeito de holograma (ou de distorção óptica da imagem real) produzido pela junção entre o que narrador tem diante de si e a profusão de referências literárias e mitológicas presente no texto. São muitas - e bastante heterogêneas essas referências: a Odisseia, Cicero, Dante, Diderot, Goethe, Dickens, Poe, Pascal etc. Nesta exposição, centro-me no diálogo de Nerval com Sterne, que é mencionado uma única vez no texto. A propósito dos percursos que teria de fazer para ir até um lugarejo próximo a Paris, o

\footnotetext{
${ }^{11} \mathrm{NPl}$ III, p. 4.

${ }^{12}$ Emenda pela qual se proibia a publicação de romans-feuilletons. Nerval joga com essa proibição, propondo-se a escrever um romance histórico (gênero aceito pelo regime) tendo como base um livro histórico que folheara na feira de livros de Leipzig. Ocorre que a narrativa de Angélique se converte na busca - digressiva e fracassada - pelo livro histórico, em livrarias e bibliotecas parisienses. Trata-se, por essa via, de uma narrativa sobre a impossibilidade da narrativa diante das restrições à liberdade de expressão que os escritores do período enfrentavam.
} 
narrador diz o seguinte: "A célebre espiral do cabo Trim não era mais caprichosa que o caminho que se tem de fazer, por um lado ou por outro." ${ }^{13}$.... Trata-se de uma única referência, mas que seria decisiva por permitir a figuração tanto dos percursos no espaço que acompanhamos ao longo da leitura de Les Nuits d'octobre, quanto do desenho geral da narrativa, ela mesma sinuosa. Mas ocorre ainda, como se verá adiante, que não se pode compreender o texto de Nerval - e a presença, nele, da leitura de Sterne - sem atentar para as tensões do momento social e político em que ele é escrito.

Feitas então essas considerações iniciais a respeito da recepção de Sterne na França, da confluência das imagens de ambos os escritores e do modo de ser de ambas as narrativas, passo então à leitura Les Nuits d'octobre à luz do momento político em que o texto é escrito, e explorando o contraponto com a Viagem Sentimental de Sterne.

Parto das passagens em que a política e a questão da ordem social estão mais imediatamente visíveis no texto: elas se fazem presente na temática da prisão e nos chamados ao silêncio e à ordem, como o "Taistoi!" [Cale-se!] com que se encerra como V e regulamento de uma goguette (um tipo de festa popular da Paris da época), sobre o qual o narrador afirma, não sem ironia: "Achamos essas disposições muito sábias" ${ }^{14}$. A ironia também parece ser a marca de quase todas as menções à "gentileza" dos guardas e agentes de polícia com os quais o eu-narrador vai cruzando em seu percurso por Paris e arredores, após o golpe de estado de Luís Napoleão.

Mas a primeira referência direta à política situa-se logo no primeiro capítulo, no seguinte trecho: "Logo já havia lido a política dos jornais, e pus-me então a folhear negligentemente a Revue Britanique. O interesse de algumas páginas, traduzidas de Dickens levou-me a ler um artigo intitulado "A chave da rua"" 15 . Ora, essa passagem pode nos fornecer uma chave para a interpretação da narrativa como um todo. Acompanhemos mais de perto os movimentos da escrita que precedem e sucedem ao trecho: o narrador (e nós leitores) chegamos ao artigo de Dickens - que irá pontuar todo o restante da narrativa - de forma inteiramente casual. A mesma disposição negligente marcaria o modo como ele lera, en passant, a política dos jornais. Estamos na segunda página do texto, e o eu-narrador já perdeu o trem, a carruagem... e se põe tranquilamente a ler. A desatenção é demasiadamente acentuada para não suspeitarmos de que ele se vale aqui do modo irônico, que se deixa captar por uma série de deslocamentos: passa-se da política (dos jornais) para um artigo de Dickens, passa-se de Paris para Londres.... Mas parece que a mudança de assunto não se opera inteiramente, e que a política da França às vésperas do Segundo Império não deixará de se inscrever no texto mais

\footnotetext{
${ }^{13}$ Les Nuits d'octobre, NPl III, p. 345.

${ }^{14}$ Les Nuits d'octobre. NPl III, p. 324.

15 p. 314.
} 
profundamente do que por uma simples menção de algo que se lê en passant.... Como quer que seja, a lógica dos deslocamentos prossegue na sequência do texto, em que o esforço de representação realista dos basfonds da sociedade francesa (à maneira de Dickens) vai cedendo espaço à mise-en-scène do sujeito, aos efeitos e às impressões causados pelo que ele vivencia em seu percurso cada vez mais infernal. De deslocamento em deslocamento, acompanhamos o abandono dos assuntos e dos objetivos apontados (política dos jornais, viagem a Meaux, narrativa realista e propósito inicial de "daguerréotyper" a realidade ${ }^{16} . .$. ). Mas a realização de uma leitura que procure ler o verdadeiro sentido desses deslocamentos pode nos levar à compreensão das razões mais profundas pelas quais, no texto, o percurso excêntrico e sem objetivo preciso vai se transformando em um percurso concêntrico e descendente, pelos andares de baixo da escala social e pelos abismos interiores. E tal leitura deve então nos conduzir à política e a uma visão da sociedade, já não captada pela lente do realismo do daguerreótipo, mas pelo "barômetro que se aplica à alma", registrando a pressão do ambiente político no qual o texto é escrito: à véspera do plebiscito que transformará Luís-Napoleão em Imperador. Vejamos.

\section{Barômetro}

"Aplicarei o barômetro à minha alma" - assim Rousseau enuncia o seu projeto na primeira das Rêveries du promeneur solitaire. ${ }^{17}$ A metáfora meteorológica foi criada por Rousseau, mas na climatologia da alma que encontramos em Sterne, o eu não é um promeneur solitaire, e sim um viajante sympathetic ${ }^{18}$. Esse sujeito poroso interage com os outros, deixase levar pelo acaso, pela oscilação dos próprios humores e - sobretudo observa-se em todos esses movimentos, em uma constante alternância entre representação do mundo e mise-en-scène do eu. É a confluência de

\footnotetext{
16 Capítulo XVI, p. 335: "Se todos esses detalhes não fossem exatos, e se eu não buscasse aqui daguerreotipar a realidade, quantos recursos romanescos não me forneceriam esses dois tipos da infelicidade e do embrutecimento!".

${ }^{17}$ Jean-Jacques Rousseau. Euvres complètes I. Organização de B. Gagnebin et M. Raymond. Paris, Gallimard (Bibliothèque de la Pléiade), 1959, pp. 1000-01. A imagem é retomada por Baudelaire em 1851, para se referir a outro leitor de Sterne, o "viajante entusiasta" E.T.A. Hoffmann, "que construiu um singular barômetro psicológico destinado a representar as diferentes temperaturas e fenômenos atmosféricos de sua alma.". Charles Baudelaire. Euvres complètes I. Ed. de Claude Pichois. Paris, Gallimard (Bibliothèque de la Pléiade), 1975, p. 378.

${ }^{18}$ Tal leitura do caráter especialmente sensível e empático do eu narrador de Uma viagem sentimental pode certamente ser contestada, apontando-se para a possível ironia de Sterne ao situar o eu-narrador nessa posição. O objetivo aqui, no entanto, é acompanhar alguns modos pelos quais o texto foi lido. No século XIX francês, tal leitura (pela via da empatia) da Viagem de Sterne é corrente. E não deixa de ser curioso notar que ela será adotada no século XX, pelas mãos de uma leitora tão arguta quanto Virginia Woolf, ainda que em tom de ressalva: "Assim sendo, em Uma Viagem sentimental nunca nos é permitido esquecer que Sterne é acima de todas as coisas sensível, simpático, humano; que acima de todas as coisas preza a decência, a simplicidade do coração humano. (...) Na realidade, a principal falha de Uma viagem sentimental vem do interesse de Sterne por nossa boa opinião sobre seu coração.". "A viagem sentimental", O leitor comum, Rio de Janeiro, Graphia, 2007. Trad. Luciana Viégas, p. 120.
} 
todas essas características que confere à narrativa o seu desenho fragmentário e caprichoso, pois qualquer ordenação linear é constantemente subvertida em favor da interação entre o indivíduo e o que o cerca. ${ }^{19}$ Essa mesma dinâmica preside a escrita de Les Nuits d'octobre, ao menos aos olhos de contemporâneos de Nerval, como Champfleury et Théophile Gautier, que o aproximaram de Sterne pela via da feição humorística e caprichosa de alguns de seus textos. Mas a escrita de Les Nuits d'octobre pode ainda ser iluminada ainda por outros contrapontos com o texto de Sterne, que devem nos levar a refletir sobre a identidade do $\mathrm{eu}$ viajante em ambas as narrativas.

\section{Un homme qui rit ne sera jamais dangereux}

Em Viagem sentimental através da França e da Itália, é apenas quando já está em Paris (capítulo 32), que Yorick se dá conta de que saíra de Londres sem o passaporte. Na tentativa de obtê-lo, resolve pedir ajuda a um certo conde de $\mathrm{B}^{* * *}$. Ao entrar no gabinete deste, observa que, sobre a mesa, havia alguns volumes de Shakespeare. Quando é perguntado sobre seu nome, abre o volume de Hamlet, aponta para o ocorrência do nome 'Yorick' e diz, em francês: "- Voici!" O conde providencia imediatamente o passaporte, ponderando que "Um homem que ri nunca será perigoso" ["Un homme qui rit ne sera jamais dangereux." ${ }^{20}$. Em vão o narrador nega ao seu interlocutor que aquela seja sua identidade - e ele terá de prosseguir viagem com aquele documento de identidade: "Como o passaporte era endereçado a todos os vice-governadores, governadores, capitães-mores (...) para que deixassem o Sr. Yorick, o bufão do rei, e sua bagagem, prosseguir em paz - admito que o triunfo de obter o passaporte foi um tanto deslustrado por minha aparência, mas não há nada sem mistura neste mundo". ${ }^{21}$ Sublinhemos a mistura de alegria e de desconcerto que se instaura na alma do humorista e atentemos para o fato de que o incômodo parece advir (ainda que ironicamente) da imputação de uma identidade - a de bobo da corte - com a qual ele tem de se lidar na continuação do seu percurso. Mas podemos pensar que a máscara de Yorick teria sido voluntariamente assumida pelo escritor Sterne, simbolizando a sua própria identidade literária, em uma operação pela

\footnotetext{
${ }^{19}$ Um outro trecho do ensaio de Virginia Woolf sublinha muito bem algumas características do texto sterniano que nos interessam aqui, apontando também para a modernidade do "método" sterniano : "É assim que Sterne transfere nosso interesse do exterior para o interior. (...) Ao preferir os meandros de sua própria mente ao guia de viagens e às bifurcações das rodovias, Sterne é particularmente de nossa época (...), sua escolha é caprichosa e individual, mas nenhum realista conseguiu ser mais brilhantemente bem sucedido na impressão do momento (...) E embora o voo desta mente errante seja tão ziguezagueante quanto o de uma libélula, não se pode negar que esta libélula tenha algum método em seu voo (...). Sorrimos, choramos, zombamos, simpatizamos por etapas. Mudamos de uma emoção para a outra num piscar de olhos." Idem, pp. 118-19.

${ }^{20}$ Em francês no original.

${ }^{21}$ Viagem sentimental [A Sentimental Journey], capítulo "O passaporte". Tradução do trecho feita por Daniel Lago Monteiro.
} 
qual a condição socialmente inferior permitiria uma abertura de espaço para a liberdade do espírito e da palavra. Ela pode ser tanto mais eficaz como arma crítica por ser aparentemente inofensiva: "Un homme qui rit ne sera jamais dangereux".

Também o viajante nervaliano se encontra frequentemente às voltas com as autoridades: em Angélique, ele viaja sem documentos, fato que, em Les Nuits d'octobre faz com que seja preso. É no sonho que tem na prisão que a interrogação a respeito própria identidade se dá sob a pressão da presença de três figuras da autoridade e da imputação, por três espectros acusadores, de uma identidade: "Fantasista! realista!! ensaísta!!!" ["Fantaisiste! réaliste!! essayiste!!!"] 22 Poderíamos resumir o teor da acusação de fantaisiste et essayiste como uma condenação à originalidade e também à excentricidade do percurso da própria narrativa até este momento. Concretamente, o eu-narrador é preso, mas a prisão ameaça a liberdade de movimentos tanto da flânerie quanto da escrita. Ao arbítrio do poder, porém, é sempre possível responder com o riso e a liberdade da fantasia do fou du roi [bobo da corte]. Por essa via, poderíamos compreender, no sonho, a tentativa de responder à acusação mediante a invocação de três "fantaisistes classiques": Luciano, Rabelais e Erasmo (seria possível acrescentar aqui Sterne). É possível ir um pouco mais longe e fazer ressoar no texto de Les Nuits d'octobre a frase de Viagem Sentimental ("Un homme qui rit ne sera jamais dangereux"), que, por sua vez, pode ecoar outras duas, uma delas atribuída a Nerval: "Conformar-se com o bastão de um bobo da corte é prudente em certas épocas" ${ }^{23}$ e outra, de $O$ Sobrinho de Rameau, de Diderot, texto tão presente em Les Nuits d'octobre: "Não há melhor papel diante dos grandes que o de bobo da corte". ${ }^{24} \mathrm{O}$ papel desempenhado, o bastão e a máscara de bobo (e do louco) podem ter os seus inconvenientes, mas podem também ter vantagens...

Ressaltemos a ambiguidade da identidade assumida (ou imputada) do fou du roi: ela pode ser a chave para a liberdade de movimentos (em diferentes planos), mas não deixa de ter um caráter incômodo, pela posição de inferioridade e marginalidade social em que o eu é colocado. Esta posição (em sua ambiguidade entre eu-narrador e escritor) é também a do eu de Les Nuits d'octobre, ao qual se poderiam aplicar as palavras iniciais do primeiro estudo de Baudelaire sobre Edgar Allan Poe, que foi publicado na Revue de Paris alguns meses antes da publicação de nosso

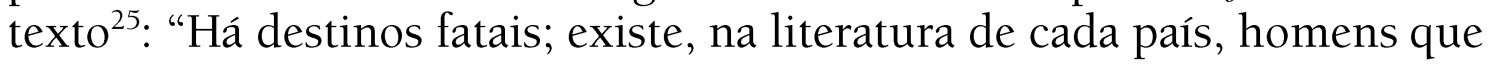

\footnotetext{
${ }^{22}$ Les Nuits d'octobre, p. 348.

23 "S'accommoder de la marotte d'un fou est prudent en certains temps".Textes attribués à Gérard de Nerval (Pensées). NPl III, p. 782.

24 "Il n'y a point de meilleur rôle auprès des grands que celui de fou". Denis Diderot. Le Neveu de Rameau. Paris, Gallimard (Folio), 1972, p. 85. Édition de J. Varloot et N. Évrard. Atente-se para a ambiguidade, em francês, da palavra 'fou', que pode se referir tanto ao bobo (da corte) ou bufão do rei quanto ao louco. Optamos aqui pela tradução bobo da corte, mas nos trechos de Nerval e de Diderot, há certamente um jogo com o duplo sentido, que pode ocorrer também em inglês (fool).

${ }^{25}$ Em março e abril de 1852 ,
} 
trazem a palavra má-sorte [guignon] escrita em caracteres misteriosos nas dobras de suas testas, e sobre os quais a sociedade lança um anátema especial, arguindo contra eles vícios de caráter que a perseguição lhes conferiu" 26 . Mais tarde, o próprio Baudelaire aproximará diretamente os destinos de Poe e de Nerval, mas é possível que a refêrencia ao nome de Poe, que aparece "vagamente" no segundo sonho de Les Nuits d'octobre, traga para o texto a ressonância do artigo de Baudelaire. Como quer que seja, no sonho se pronuncia claramente um anátema análogo, assim como a imputação de uma identidade que parece confinar o indivíduo à condição de pária.

Em Nerval, como bem sintetizou Raymond Jean, a identidade do eu, "cambiante e frequentemente ameaçada", reflete uma existência material precária, numa época em que "a obra intellectual (...) transformada em mercadoria (...) depende do público que a compra, e ao qual o escritor deve submeter-se mascarando com frequência sua própria personalidade. Mais do que ninguém, Nerval viveu essa situação, o que explicaria a dupla face, a ambiguidade e a originalidade de sua obra" 27 . Ora, essa identidade "cambiante e frequentemente ameaçada" se faz presente de modo exemplar em Les Nuits d'octobre, e a comparação com Sterne pode mais uma vez ajudar.

Em Sterne, a identificação ao bobo da corte ocasionara um incômodo circunstancial: a identidade imputada não o impede se prosseguir viagem, em conforto e segurança, acompanhado de seu criado francês. Em Nerval, a proximidade real do eu-narrador com indivíduos que ocupam a escala mais baixa da sociedade - artistas populares, saltimbancos e vagabundos com os quais ele se solidariza ao longo de Les Nuits d'octobre - traduz a condição concreta de boa parte de sua existência como escritor. A ele, a exclamação "- Pobre Yorick!" se aplicaria em um sentido que iria bem além do simbólico. Assim, o texto de Nerval traz as marcas dolorosas do contexto histórico em que o é escrito, marcas que conferem ao texto uma espessura e un páthos bem diverso de A Viagem Sentimental. O eu-escritor, sujeito a privações materiais, vive também concretamente a ameaça à liberdade de movimentos e de palavra (e à própria identidade). É sob essas condições que ele medirá "as diferentes temperaturas e os fenômenos atmosféricos de sua alma". Consideremos essa mesma questão de um outro ponto de vista, atentando para as diferenças entre A Viagem sentimental et Les Nuits d'octobre no que diz respeito ao tema da prisão, que ocupa o centro de ambas as narrativas, e que era um tema recorrente na literatura romântica da França, como mostra o livro intitulado La prison romantique, de Victor Brombert ${ }^{28}$.

\footnotetext{
${ }^{26}$ Charles Baudelaire. "Edgar Poe, sa vie et ses œuvres". In: Euvres Complètes II, edição de Claude Pichois. Paris, Gallimard (Bibliothèque de la Pléiade), 1976, p. 249.

${ }^{27}$ Raymond Jean. La poétique du désir. Nerval, Lautréamont, Apollinaire et Éluard. Paris: Seuil, 1974, pp. 47-48.

${ }^{28}$ Victor Brombert. La prison romantique: essai sur l'imaginaire. Paris, José Corti, 1975.
} 


\section{A prisão}

Em Sterne, a famosa série de meditações sobre o cativo é ensejada pelo fato de que o eu-narrador esquecera em Londres o seu passaporte, o que poderia levá-lo à prisão na Bastilha. ${ }^{29}$ Diante de tal ameaça, Yorick centra sua atenção em uma voz cuja origem desconhece, mas que parece dizer-lhe "I can't get out". Então descobre que a queixa vem de um pássaro em uma gaiola, um estorninho que lhe diria "Não posso sair". Segue-se uma longa meditação a respeito das misérias da prisão e da escravidão. Essa meditação prossegue no capítulo subsequente, ("O prisioneiro"), no qual lemos as seguintes palavras: "O pássaro na gaiola perseguiu-me até meu quarto; sentei-me junto à mesa e, apoiando a cabeça na mão, comecei a imaginar comigo as penúrias da prisão. Estava com a justa disposição para isso, e então deixei a minha imaginação correr solta" ${ }^{30}$. A frase de Yorick sintetiza e permite exemplificar o que poderíamos aqui denominar como método sentimental de Sterne, ao menos como ele teria sido percebido por escritores franceses do período ${ }^{31}$ : o sujeito coleta, da realidade, um elemento que desperta sua sensibilidade: "O pássaro na gaiola perseguiu-me até meu quarto" e, no recolhimento do quarto, ele põe-se a meditar sobre as misérias do prisão. Trata-se aqui menos de uma reflexão abstrata sobre o tema do que de um esforço de figurar para si mesmo o sofrimento de um único cativo, no qual se concentra sua imaginação. Esse procedimento - em que prevalece a particularização e o apelo à sensibilidade e à imaginação - teria sido explorado com propósitos ideológicos em algumas narrativas francesas (às quais aludi no início deste artigo) do período revolucionário e pós-revolucionário, na passagem do século XVIII ao XIX. Mas seria possível reconhecer um procedimento análogo em Les Nuits d'octobre?

Os temas da prisão, do fechamento e da vigilância pontuam a narrativa de Nerval: na figura dos porteiros, na prisão que o narrador presencia no cabaré Paul Niquet e nos capítulos finais, com o seu próprio encarceramento. Mas nesses capítulos, o espaço da prisão traz uma abertura: não apenas para a imaginação - como em Sterne e sua figuração da cativo - mas para o sonho, ou melhor, o pesadelo. O caminho que se abre na "noite profunda da cela" conduz-nos à mise-en-scène de um tribunal (vivido em camadas mais profundas da consciência) no qual se profere o anátema ao escritor e às suas "obras malditas". Tanto quanto a própria prisão, importa a ressonância subjetiva dessa experiência: é a ela

\footnotetext{
${ }^{29}$ Sterne viajou para a França durante a Guerra dos Sete anos (entre França e Inglaterra). Agradeço a Thiago Rhys Bezerra Cass por atentar para a necessidade de ressaltar este fato.

${ }^{30}$ Viagem Sentimental. São Paulo: Hedra, 2009, p. 98. Trad. Luana Ferreira de Freitas, introdução L.F. Freitas e W. Costa.

${ }^{31}$ A respeito de Sterne, Baudelaire afirma: "Este homem criou seu método". "Études sur Poe" ["Présentation de Révélation Magnétique"] Charles Baudelaire. Euvres complètes II. Ed. de Claude Pichois. Paris: Gallimard (Bibl. de la Pléiade), 1976, p. 247.
} 
que o leitor tem acesso na narrativa do tribunal do sonho, que, deslocando e condensando os restos diurnos, parece revelar mais profundamente o gênero de ameaça e perseguição (bem real) que paira sobre o escritor às vésperas do Segundo Império. Aqui, como em Sterne, as misérias da prisão são tematizadas pela representação de uma experiência particular de encarceramento e sua ressonância subjetiva. Contudo, sendo o cativo o próprio narrador-escritor, tal vivência se torna, em Les Nuits d'octobre, talvez mais aguda, pois já não se trata de um olhar sympathetic para as misérias da prisão (como preconiza, não sem ironia, Sterne), mas de um olhar por dentro: da prisão e das marcas que ela pode deixar no sujeito. ${ }^{32}$

De maneira mais geral, a atmosfera captada em Les Nuits d'octobre (ou construída pelo texto) se distingue da Viagem sentimental por seu caráter mais opressivo e desencantado - semelhante a um "canto à beira do abismo" 33 . É o que parece nos dizer, no penúltimo parágrafo da narrativa, o tratamento dado ao motivo do pássaro: "A mulher do taverneiro mostrou-me uma lontra empalhada, completando uma coleção de bichos e pássaros do Valois que ele espera vender a algum inglês"34. A nota final da narrativa - nota de desencanto - recai nesses pássaros empalhados e reduzidos à condição de mercadoria, e nos quais se espelha o destino da imaginação literária e de um escritor como Nerval nos anos de 1850.

A prisão em Les Nuits d'octobre pode ser lida como um ponto de chegada do percurso pelos bas-fonds da sociedade francesa, percurso no qual, solidarizando-se com indivíduos situados nos andares mais baixos da sociedade, o eu-narrador dela sente e vive a pressão muito concretamente. Essa experiência, que parece se furtar à lente do daguerreotipo, vai sendo recolhida ao longo do caminho por um eu poroso. O modo pelo qual se dá essa coleta - ou esse registro - da realidade está sintetizado nos sonhos de Les Nuits d'octobre, em grande medida constituídos por restos diurnos (ou mais precisamente "noturnos"). Mas a prosa porosa de Les Nuits d'octobre é toda ela construída por uma alternância (que chega ao nível da frase) entre o interno e o externo, entre a observação do mundo e a observação do sujeito. Isso se dá em muitos momentos por uma modalidade de escrita marcada por aquilo que Northrop Frye (com referência a Sterne, entre outros) denominou ritmo associativo ${ }^{35}$, e que se encontra por exemplo em um trecho situado entre os capítulos que trazem o número XVI (são dois). Uma leitura detida do trecho nos permite considerar mais de perto a escrita-barômetro de Les

\footnotetext{
${ }^{32}$ Vale dizer que o narrador sterniano tampouco estaria inteiramente confortável por estar sem documentos em uma viagem à França durante uma guerra entre França e Inglaterra. Mas em Uma viagem sentimental, o fato de estar sem documentos não tem maiores consequências e ele pode prosseguir seu percurso na companhia de seu criado francês.

${ }^{33}$ Les Nuits d'octobre, p. 326

34 p. 351.

35 Verbete "Verse and Prose". In: Princeton Encyclopedia of Poetry and Poetics, Alex Preminger (org.). Princeton University Press, 1974.
} 
Nuits d'octobre e deve lançar alguma luz sobre a atmosfera obscura e enigmática construída pelo texto, que pode ser lida como uma tradução subjetiva do clima político em que ele é escrito.

\section{A escrita humorística}

Na narrativa de Les Nuits d'octobre (assim como Lorely e Promenades et Souvenirs) são muito recorrentes as considerações sobre o clima e a variação de luminosidade. Em tais considerações talvez possamos ler as marcas da existência precária e sem residência fixa que foi, por tanto tempo, a do próprio Nerval. Essa sensibilidade meteorológica é perceptível em todo o trecho que será comentado a seguir ${ }^{36}$, e a partir do qual retornarei a algumas das questões tratadas anteriormente.

Le soleil commence à percer le vitrage supérieur de la salle, la porte s'éclaire. Je m'élance de cet enfer au moment d'une arrestation, et je respire avec bonheur le parfum des fleurs entassées sur le trottoir de la rue aux Fers. (...) Je crois qu'il est temps de me diriger vers l'embarcadère de Strasbourg, emportant dans ma pensée le fantôme de cette nuit.

(...) Voilà, voilà, celui qui revient de l'enfer! Je m'appliquais ce vers en roulant le matin sur les rails du chemin de Strasbourg, - et je me flattais... car je n'avais pas encore pénétré jusqu'aux plus profondes souricières; je n'avais guère, au fond rencontré que d'honnêtes travailleurs, - des pauvres diables avinés, des malheureux sans asile... Là n'est pas encore le dernier abîme.

L'air frais du matin, l'aspect des vertes campagnes, les bords riants de la Marne, Pantin à droite, d'abord, - le vrai Pantin, — Chelles à gauche, et plus tard Lagny, les longs rideaux de peupliers, les premiers coteaux abrités qui se dirigent vers la Champagne, tout cela me charmait et faisait rentrer le calme dans mes pensées.

Malheureusement un gros nuage noir se dessinait au fond de l'horizon, et quand je descendis à Meaux, il pleuvait à verse. Je me réfugiai dans un café, où je fus frappé par l'aspect d'une énorme affiche (...)

(...) À défaut d'autre spectacle, je voulus vérifier par moi-même les merveilles de cet affiche, et je ne sortis de la représentation qu'après minuit.

O sol começa a penetrar pela vidraça superior da sala, a porta se ilumina. Escapo desse inferno no momento de uma prisão, e respiro com satisfação o perfume das flores amontoadas na calçada da Rue aux Fers (...). Creio já ser o momento de me dirigir à plataforma de Estrasburgo, levando no pensamento o fantasma dessa noite.

(...). Vejam! Vejam! Aquele que retorna do inferno! Eu aplicava a mim mesmo esse verso rodando de manhã sobre os trilhos da estrada de Estrasburgo. E enganava a mim mesmo... pois não havia ainda penetrado nas mais profundas armadilhas para bandidos; encontrara apenas trabalhadores honestos e infelizes desabrigados... Aquele ainda não era o último abismo.

\footnotetext{
${ }^{36}$ Passagem situada entre as páginas 335 e 337 de Les Nuits d'octobre.
} 
$\mathrm{O}$ ar fresco da manhã, a visão dos campos verdejantes, as margens vicejantes do Marne. Primeiro Pantin, à direita - a verdadeira Pantin Chelle à esquerda, e, mais adiante Lagny, as longas cortinas de choupos, as primeiras encostas abrigadas que se dirigem à Champagne; tudo isso me encantava e devolvia a calma aos meus pensamentos.

Infelizmente uma grande nuvem negra se desenhava ao fundo do horizonte, e quando desci em Meaux, chovia a cântaros. Refugiei-me em um café, onde um enorme cartaz vermelho, concebido nos seguintes termos, chamou-me a atenção [...]

À falta de um outro espetáculo, quis verificar por mim mesmo as maravilhas daquele cartaz, e só fui sair da representação depois da meia noite.

O trecho se inicia com o "sol, que começa a atravessar a vidraça superior da sala" (de um cabaré popular). Na frase seguinte já se esboça uma tensão entre um movimento desimpedido e rápido ("je m’élance"I "lanço-me", "escapo") e a restrição ao movimento ("prison"): "escapo desse lugar no momento de uma prisão". Note-se ainda que a palavra "enfer" contradiz a expectativa criada pelo sol, que se insinuava no ambiente. Já na rua, vem a satisfação e o alívio com o "parfum des fleurs". Mas as flores estão empilhadas na calçada da "rue aux Fers" ("Rua dos ferros") (sublinhemos a homofonia que vincula elementos contrastantes: enfer, bonheur, fleur, fer/ inferno, felicidade, flor, ferro). Mais adiante, voltamos então à escuridão (já sugerida pelo enfer), com o "vão fantasma desta noite": é um fantasma noturno (a própria noite) que aparece em plena luz do dia, e como que afugenta o perfume das flores, alívio temporário oferecido pelo mundo exterior. Parece de fato não haver como escapar. Já na estrada, o inferno da noite em claro nos bas-fonds de Paris o persegue na forma de um verso que não lhe sai da cabeça: "Voilà, voilà, celui qui revient de l'enfer!" ("Eis aqui aquele que retorna do inferno!"). Esse "inferno" parece provisoriamente se atenuar: "je n'avais guère, au fond, rencontré que d'honnêtes travailleurs ..." ("no fundo, não havia encontrado senão trabalhadores honestos..."). Logo vem, no entanto, a observação de que o pior estava por vir: "Là n'était pas encore le dernier abîme" ("Aquele não era o último abismo"). A paisagem, que vai mudando à medida que o sujeito se movimenta sem obstáculos aparentes, consegue devolver a calma aos seus pensamentos até que, em nova inversão, "un gros nuage noir" ("uma grande nuvem negra") faz o tempo virar, obrigando o eu-narrador a refugiar-se em um café. Quando saiu do café, já era mais de meia-noite. ${ }^{37}$ É significativo que essa experiência de um percurso subjetivamente sem saída venha logo em seguida ressurgir, condensada e deslocada, no trecho relativo ao sonho (cap. XVII "Capharnaüm"): "Monter, descendre, ou parcourir les corridors, et cela

\footnotetext{
${ }^{37}$ Neste último parágrafo retomo o comentário (do trecho de Les Nuits d'octobre) que está contido em meu livro, intitulado Gérard de Nerval: a poesia em trânsito. São Paulo: Ateliê, 2009. O desenvolvimento mais completo deste comentário, que apresento no que se segue, ocorreu-me posteriormente à publicação do livro, razão pela qual foi preciso retomá-lo neste artigo.
} 
pendant plusieurs éternités... Serait-ce la peine à laquelle se serai condamné pour mes fautes?" ("Subir, descer, ou percorrer os corredores, e durante muitas eternidades... Seria a pena à qual estaria condenado por meus erros?")

Como quer que seja, no trecho, e em sua vertiginosa variação de atmosfera (interna e externa), podemos observar mais de perto a "a nova língua inventada", no folhetim nervaliano, "para a subjetividade da experiência da cidade" 38 . Nele se vê a originalidade da escrita humorística de Les Nuits d'octobre, pela qual se constrói uma estranha atmosfera que abarca desde os abismos do sujeito até as tensões mais profundas da sociedade, exprimindo, assim, "um estado de terror inexprimível" ${ }^{39}$. Mais particularmente, a imagem da "grande nuvem negra", que "infelizmente" se desenhava no horizonte, faz pensar no plebiscito que ocorreria algumas semanas depois da publicação do texto ${ }^{40}$, plebiscito que restabelece "dignidade imperial na pessoa de Luís-Napoleão Bonaparte" com cerca de $97 \%$ dos votos. Tal resultado certamente não abriria para um escritor como Nerval um horizonte luminoso.

\section{A espiral e os círculos.}

Do complexo trajeto narrativo de Les Nuits d'octobre retomei alguns pontos de confluência com a Viagem sentimental de Sterne. Tal confluência se dá do ponto de vista temático, pela interrogação em torno da identidade do sujeito e sua proximidade com indivíduos marcados por certa marginalidade, assim como pela revisitação do tópos da prisão; mas ela também é perceptível na forma que assume a escrita nervaliana, sentimental e humorística à sua maneira. Em todos esses pontos, o texto de Nerval opera deslocamentos significativos em relação ao ponto de partida sterniano, deslocamentos que podem ser lidos sobre o fundo do contexto histórico e social em que o texto se inscreve e à luz da situação de Nerval - como escritor - na sociedade francesa do início dos anos de 1850. Gostaria de concluir essa leitura paralela de Nerval e Sterne com uma última consideração, que se pretende também uma síntese do que procurei expor.

Uma das razões do caráter desnorteante da narrativa de Les Nuits d'octobre (para o intérprete) está na atuação conjunta de dois tipos de movimentos: o primeiro - excêntrico ou digressivo - encontra-se na prosa caprichosa e nos percursos ditados pelo acaso, à maneira de Sterne. Ao segundo tipo poderíamos dar o nome de concêntrico e está sintetizado na

\footnotetext{
${ }^{38}$ Karlheinz Stierle. La Capitale des signes. Paris et son discours. Paris: Maison des Sciences de l'homme, 2001, p. 387.

39 "Un état de terreur inexprimable": as palavras são do próprio Nerval, em Angélique, referindo-se ao clima que encontrou entre os literatos de Paris após seu retorno da Alemanha, em 1850, em função da emenda Riancey, à qual me refiro no início deste artigo.

${ }^{40}$ Trata-se do segundo plebiscito, realizado em 21 e 22 de novembro de 1852, sob o governo de LuísNapoleão. Um primeiro plebiscito ocorreu em dezembro de 1851.
} 
imagem inicial do "círculo que se estreita", assim como em referências constantes aos círculos do inferno. O caráter caprichoso do desenho da narrativa é todo o tempo tensionado por uma força oposta, de modo que a espiral do caporal Trim se converte em um percurso concêntrico e descendente (infernal e dantesco), que vai conferindo-lhe nova densidade e complexidade. Na tensão entre esses dois movimentos residiria uma diferença essencial entre a Viagem de Sterne e Les Nuits d'octobre.

Ora, esse duplo traçado também corresponde uma dupla disposição do eu narrador nervaliano, que se deixa levar pelo acaso, mas também parece ser constantemente movido pelo propósito de ir até o fim da sua peregrinação pela realidade dos infernos parisienses.

Diante de uma realidade que parece todo o tempo se furtar a uma mimese ao modo do daguerreótipo (que é inicialmente referida no próprio texto), o narrador vai gradativamente abandonando o propósito realista. Mas ele não parece recuar na intenção de mergulhar no universo popular de Paris: à hesitação expressa pela frase "N'allons pas si loin" ("Não vamos tão longe") se segue, um pouco adiante, a determinação do "Allons plus loin" ("Vamos mais longe") com que se encerra o cap. X ${ }^{41}$. Frase imperativa que ecoa outra, anterior: "E agora mergulhemos mais profundamente ainda nos círculos inextricáveis do inferno parisiense" 42 Forte ed ardito (forte e ousado, como escreve Nerval, retomando Dante), o eu narrador segue adiante, até os "últimos abismos". Nessa determinação, ele se mostra consciente de uma tarefa como escritor, como se pode ler nos seguintes trechos: "Se não estivesse seguro de cumprir uma das missões dolorosas do escritor, pararia aqui (...)"; "Aos homens ricos falta com frequência a coragem para penetrar em semelhantes lugares (...). Um simples escritor não pode senão colocar o dedo nessas feridas, sem pretender fechá-las"43. Atentemos para os termos de Nerval: para além do propósito realista, a missão do escritor parece ser a de, com ousadia e coragem, penetrar (ou mergulhar) naqueles lugares tão semelhantes aos círculos infernais. A missão é cumprida na modesta condição de simple écrivain (contraposta aos hommes riches). Mas sublinhamos o fato de que ela é marcada pelo signo da dor (missão dolorosa, colocar o dedo nessas feridas). Efetivamente, o métier de realista, tal como Nerval o exerce aqui, seria penoso demais ("trop dur à faire")... Os "excessos de um realismo absoluto" ${ }^{44}$ e a impessoalidade da lente do daguerreótipo cedem então lugar à escrita sentimental e humorística. Mas, em Les Nuits d'octobre, tal escrita se abre a uma experiência abissal do real, como todos os riscos e dores que ela comporta, muito concretamente, para o sujeito.

E então podemos finalmente nos perguntar, com Karlheinz Stierle: "Mas essa 'pavorosa mistura de comédia e sonho, de sonho e de realidade'

\footnotetext{
${ }^{41}$ Les Nuits d'octobre, p. 322 et p. 328.

42 Idem, p. 321.

${ }^{43}$ Idem, p. 328 et p. 335.

${ }^{44}$ Idem, p. 351.
} 
que o eu viveu como uma realidade da cidade noturna e como realidade da consciência noturna não é, ela mesma, uma experiência necessária do real?" ${ }^{45}$. Indo além, pode-se ler nesse real vivido dolorosamente a manifestação de uma Weltschmerz. Nessa "dor do mundo" legível no texto se realiza o cruzamento entre o trajeto individual e o coletivo, pois o fracasso da representação realista (ao modo do daguerreótipo) dos basfonds da sociedade se converte na expressão de profundas tensões sociais, captadas subjetivamente. E então o texto traz as marcas da história não pela distância do testemunho - "Eu vi, foi assim". A narrativa, que conteria os rastros da experiência vivida, nos diria antes: "Eu estava lá: trago as marcas disso, e elas ainda são capazes de falar" ${ }^{46}$ E é então em sua estranheza que Les Nuits d'octobre nos faz mergulhar na realidade de uma atmosfera politicamente inquietante.

É ainda Ross Chambers quem nos ensina que "os anos de 1850 são aqueles em que a "experiência melancólica aparece (...) como uma experiência necessária do real". Tal constatação nos leva à ideia de que: "É preciso estar louco para ver claramente"47. A escrita melancólica de Les Nuits d'octobre pode ser lida à luz dessa constatação. Mas ela já não estaria enunciada no próprio texto nervaliano, que, citando-as, traz para o contexto de 1852 as máximas "consoladoras" de Pascal et de La Rochefoucauld? : "Les hommes sont fous, si nécessairement fous, que ce serait être fou par une autre sorte que de n'être pas fou" ${ }^{48}$, e "C'est une grande folie de vouloir être sage tout seul"? ${ }^{49}$. Retomando o próprio Nerval: "conformarse com um bastão de um louco" talvez seja mesmo "prudente em certas épocas". 50

\footnotetext{
${ }^{45}$ Karlheinz Stierle, Op. cit, p. 397.

46 Ross Chambers. Mélancolie et opposition. Les débuts du modernisme en France. Paris: José Corti, 1987, p. 231 .

${ }^{47}$ Idem, pp. 223 et 224.

48 “Os homens são loucos, tão necessariamente loucos, que seria louco, de outro modo, aquele que não fosse louco". (Pascal)

49 "É uma grande loucura querer ser lúcido/sábio sozinho" (La Rochefoucauld). Les Nuits d'octobre, p. 340 .

${ }^{50}$ Frase atribuída a Nerval e à qual me referi no início deste artigo. Ela traz a ambiguidade entre "louco" e "bobo da corte", já que o termo francês fou permite as duas leituras.
} 